\title{
Extracorporeal membrane oxygenation: A bleeding patient's best friend?
}

\author{
Marisa Cevasco, MD, MPH, and Hiroo Takayama, MD, PhD
}

\author{
From the Department of Surgery, Columbia University Medical Center, New York, NY. \\ Disclosures: Authors have nothing to disclose with regard to commercial support. \\ Received for publication Sept 25, 2017; accepted for publication Oct 6, 2017; available ahead of print Nov 7, \\ 2017. \\ Address for reprints: Hiroo Takayama, MD, PhD, 177 Fort Washington Ave, New York, NY 10032 (E-mail: \\ hirofu2@hotmail.com). \\ J Thorac Cardiovasc Surg 2018;155:651-2 \\ 0022-5223/\$36.00 \\ Copyright (C 2017 by The American Association for Thoracic Surgery \\ https://doi.org/10.1016/j.jtcvs.2017.10.012
}

Pulmonary endarterectomy (PEA) for chronic thromboembolic pulmonary hypertension (CTEPH) is an increasingly common procedure. CTEPH had been a rare diagnosis and was considered to be an uncommon condition, but recent data suggest that we have substantially underestimated its prevalence. Cumulative incidence may be nearly $10 \%$ after symptomatic pulmonary embolism; an additional $30 \%$ of all patients with CTEPH have no previous diagnosis of pulmonary embolism. ${ }^{1}$ With increased vigilance and screening, there is room for expansion of the patient population. Our European colleagues have led the way, with 1.7 PEAs per million of population performed annually, compared with 0.9 in the United States. ${ }^{2}$

The potential benefits of PEA for CTEPH noted by Guth and colleagues ${ }^{3}$ in their article in this issue of the Journal are impressive: rapid improvement in right ventricular afterload, gas exchange, exercise capacity, and survival. Any new technique, however, will have its downside. Complications include lung reperfusion injury, irreversible pulmonary hypertension, right ventricular failure, and catastrophic endobronchial bleeding. Yet according to Guth and colleagues, ${ }^{3}$ at least one of these complications may be abated through an unconventional approach. They describe managing intraoperative bleeding during PEA with the use of short-term venoarterial extracorporeal membrane oxygenation (ECMO).

ECMO already has many friends in a diverse patient population. Now, we learn from Guth and colleagues ${ }^{3}$ that it may be applied in patients with endobronchial bleeding after PEA. This is a novel challenge, because ECMO potentiates and induces bleeding complications, and Guth and colleagues $^{3}$ are to be commended on their innovative approach and low mortality.

In their study, 8 patients were placed on venoarterial ECMO, and all were successfully weaned from ECMO without further bleeding. Of the 8 patients, 7 lived to discharge, and only 1 died of multiorgan failure. Patients were supported on ECMO for an average of $49 \pm 13$ minutes, while heparin was reversed with fullfriends!

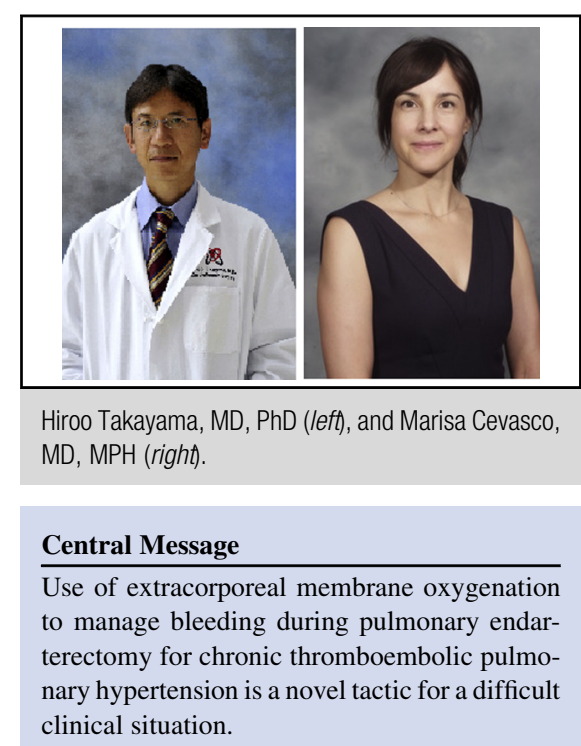

See Article page 643.

dose protamine and additional maneuvers were undertaken, such as applying fibrin glue, administering blood products, and optimizing ventilator settings.

Guth and colleagues ${ }^{3}$ somewhat arbitrarily chose a blood loss of $250 \mathrm{~mL}$ as their cut-off for severe endobronchial bleeding. We suggest, however, that catastrophic bleeding during CTEPH is greater than $250 \mathrm{~mL}$ and is a result of surgical trauma to a pulmonary vessel. ${ }^{4}$ Could mere reversal of anticoagulation and product administration be sufficient to close a hole in a pulmonary artery or arteriole?

Guth and colleagues, ${ }^{3}$ in their high-volume program, may have historically had poor outcomes after endobronchial bleeding when using conventional interventions, such as partial lung resection, embolization, or pneumonectomy. As they gained experience with ECMO in established applications, they may have become increasingly creative by applying it in "off-label" uses, such as the one described here. Likely there is an internal subjective trigger point that they use to balance the risks and benefits of ECMO.

There are caveats to keep in mind, however, such as the small sample size of the study, the expense of running ECMO (even for less than an hour), and that Guth and colleagues $^{3}$ are experienced surgeons who typically avoid potentially fatal endobronchial hemorrhage with their surgical proficiency. Despite these limitations, we are happy to note that in any event, ECMO continues to find new 


\section{References}

1. Yang S, Yang Y, Zhai Z, Kuang T, Gong J, Zhang S, et al. Incidence and risk factors of chronic thromboembolic pulmonary hypertension in patients after acute pulmonary embolism. J Thorac Dis. 2015;7:1927-38.

2. Lang IM, Madani M. Update on chronic thromboembolic pulmonary hypertension. Circulation. 2014;130:508-18.
3. Guth S, Wiedenroth CB, Wollenschläger M, Richter MJ, Ghofrani HA, Arlt M, et al. Short-term venoarterial extracorporeal membrane oxygenation for massive endobronchial hemorrhage after pulmonary endarterectomy. J Thorac Cardiovasc Surg. 2018;155:643-9.

4. Morsolini M, Azzaretti A, Orlandoni G, D’Armini AM. Airway bleeding during pulmonary endarterectomy: the "bubbles" technique. J Thorac Cardiovasc Surg. 2013;145:1409-10. 